\title{
RADIOGRAPHIC EVALUATION OF BONE QUALITY IN RHEUMATOID ARTHRITIS PATIENTS
}

\author{
Mushira M. Dahaba *, Ahmed bakry ${ }^{* *}$ and Walid S. Salem ${ }^{* * *}$
}

\begin{abstract}
Introduction: Rheumatoid arthritis is an inflammatory chronic, disease. Rheumatoid arthritis leads to swelling, stiffness, pain, and probable loss of function in numerous joints, including the TMJ. Patients on steroid medications usually suffer from: ease of infection osteoporosis and also they have a risk of the gingival inflammation at the implant sites if the patient is unable to maintain the oral hygiene measurements to control the plaque following the treatment. Due to these problems the Dentists hesitate to perform dental implant for them. Aim of the study: To evaluate the effect on the TMJ and the bone density in patients with RA and under treatment for a long time. Material and methods: 72 patients were divided into 3 groups: group A: 24 normal patients, group B: 24 patients with rheumatoid arthritis recently discovered, group C: 24 patients with rheumatoid arthritis for at least 10 years and are on a regular treatment and follow up. The angle of the mandible was measured to determine the effect on the TMJ, and some areas were selected to measure the bone density. Results: The results for the angle measurement showed a significant difference between the measured angle in the 3 groups. The biggest angles mean was group A (the control group), while the lowest mean was group C. Regarding the measured density in the 3 groups the highest density was measured in group A, while the least was measured in group C. Conclusion: There is a high correlation between the duration of the RA and the bone density and also an effect on the TMJ which affect the mandibular angle and convert the patient occlusion into skeletal class II despite receiving a treatment.
\end{abstract}

KEY WORDS: Rheumatoid arthritis, TMJ, bone density, Dental implant.

\section{INTRODUCTION}

Rheumatoid arthritis is an inflammatory chronic, ill-defined systemic disease that is supposed to be an autoimmune disease, but sometimes it may be modified by other issues such as genetics, hormones, microbes, as well as the environment. Rheumatoid arthritis showing chronic non-purulent polyarthritis, which lead to swelling, stiffness, pain, and probable loss of function in numerous joints, including the tempromandibular joint (TMJ) ${ }^{1}$ commonly linked

\footnotetext{
* Professor, Oral \& Maxilofascial Radiology, Cairo University

** Assistant Professor, Oral \& Maxilofascial Radiology, Minia University

*** Lecturer, Oral \& Maxilofascial Radiology, Beni Suef University
} 
with osteoporosis, generally needs treatment for a long time with non-steroidal anti-inflammatory drugs (NSAI) or steroid. ${ }^{2}$

It is one of the most common inflammatory systemic disease affecting the temporomandibular joint (TMJ), resulting in a malocclusion (skeletal Class-II) combined with anterior open-bite. Regarding the TMJ, the articular disc, and the articulating surfaces are surrounded with the pannus causing destruction for the disc, fossa, articular eminence, and the condyle. ${ }^{3}$ These advanced destruction in the TMJ frequently seen by the progress of many dentofacial distortions. Also, bone resorption in the condyles induces subsequent rotation of the mandible in the backward and downward direction, resulting in an anterior open-bite with a skeletal Class II malocclusion, an increased facial height, a steep mandibular plane angle, and a decreased chin projection. ${ }^{3}$

Patients on steroid medications usually suffer from: ease of infection and this may be due to decrease in the immunity in addition to osteoporosis. ${ }^{2}$ Therefore the chronic use of steroids for any reason has been cited as one of the contraindications for dental implant treatment. ${ }^{4}$

The patients on steroids are prone to infection, and also they have a risk of the gingival inflammation at the implant sites if the patient is unable to maintain the oral hygiene measurements to control the plaque following the treatment. This is the reason which makes many Dentists hesitate when dealing with patients taking steroids to perform dental implant treatment. However, if the patient was able to maintain good oral hygiene measurements to control the plaque after the treatment similar to healthy people, in spite of being unable to properly grasp a toothbrush with his deformed fingers, the patient's efforts may contribute to the success of the implant procedure, this emphasis that the oral hygiene measurements being an important factor for successful dental implant treatment in all patients even those taking steroids. ${ }^{2}$
The inflammatory periodontal disease and the RA are chronic inflammatory conditions with many common pathological pathways. Although the originating causes of these 2 diseases are clearly different, both are intensified by a disproportion in proinflammatory and anti-inflammatory cytokines. 5 Clinical and epidemiological data support a link between these two conditions. ${ }^{6}$ Similar cytokine profile with high levels of proinflammatory cytokines, including TNF-a and IL-1b and low levels of circulating anti-inflammatory cytokines, for example IL-10, have been stated in both conditions . ${ }^{5} \mathrm{~A}$ bidirectional relationship has been suggested to exist between periodontal disease and RA, although findings so far remain equivocal. ${ }^{7-11}$

\section{AIM OF THE STUDY}

The present study was conducted to evaluate the effect of RA and its treatment on the TMJ and the bone density. And also to compare between the patients under steroid medication for a long time and the newly discovered RA patients, regarding the TMJ and the bone density.

\section{SUBJECTS AND METHOD}

\section{Patient's selection:}

72 patients were selected from the out-patient clinic in the university hospital in Menia University from the rheumatoid clinic.

The patients were divided into 3 groups:

- Group A: 24 normal patients (control group).

- Group B: 24 patients with rheumatoid arthritis recently discovered

- Group C: 24 patients with rheumatoid arthritis for at least. 10 years and are on a regular treatment and follow up.

CBCT images were performed using Sordex Scanora 3D unit. The following settings were used for the CBCT imaging: $120 \mathrm{KV}$; $5 \mathrm{~mA}$; 
FOV: 130 X 145mm (3D XL) standard resolution; voxel dimension $0.35 \mathrm{~mm}$; exposure time 4.5 Sec, with the patient in a seated position.

\section{Image Analysis:}

The image analysis and the measurements obtained were performed by 3 Radiologists expert in interpreting CBCT images. Then all the measurements were completed twice by each observer at 2 different sessions with a 2 weeks interval in between the 2 sessions. All the measurements were done in a blind technique. Results from these 2 trials were analyzed statistically to reveal the intra-examiner (between each observer and himself) reliability and diagnostic performance.

The inter-examiner reliability and diagnostic performance were also tested between the measurements of the 3 observers.

All the measurements were completed using the OnDemand software.

\section{Effect on the mandible due to TMJ problems:}

A tangent line was drawn parallel to the posterior part of the ramus and another line was drawn tangential to the inferior border of the mandible. The angle formed by intersection of the 2 lines was measured. For each patient we have a right and left reading, the average was taken. As shown in fig. 1.

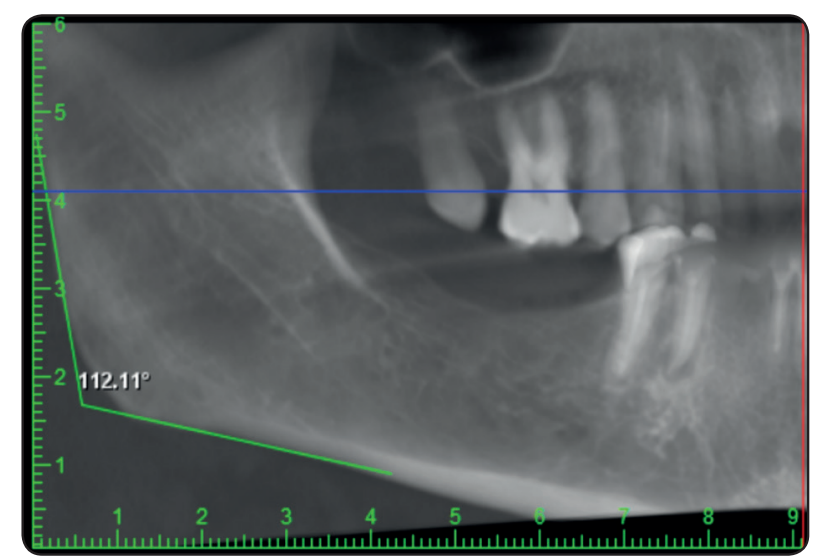

Fig (1): Measuring the angle of the mandible using a tangent line parallel to the posterior part of the ramus and another line drawn tangential to the inferior border of the mandible.

\section{Bone Density:}

For each patient four areas (two on each side) were marked and the average relative bone density value was calculated using On Demand software:

1. A rectangle below the molar area and above the inferior mandibular canal with dimension $0.5 \times 1.5 \mathrm{~cm}$

2. A square at the ramus area with dimensions $1 \mathrm{X} 1 \mathrm{~cm}$ at the angle area.

For each patient, we have right and left readings, the average was taken. As shown in fig. 2.

\section{RESULTS}

In this study, 72 patients with RA were enrolled. They were divided into 3 groups according to the duration of disease discovering.

The results for the angle measurement were shown in table 1 , and summarized in chart 1 . The ANOVA test showed a significant difference between the measured angle in the 3 groups. The biggest mean was in group A (control group), while the lowest mean was group C (RA more than 10 years). Further analysis between each group and the second showed a significant difference between each group as shown in table 2 .

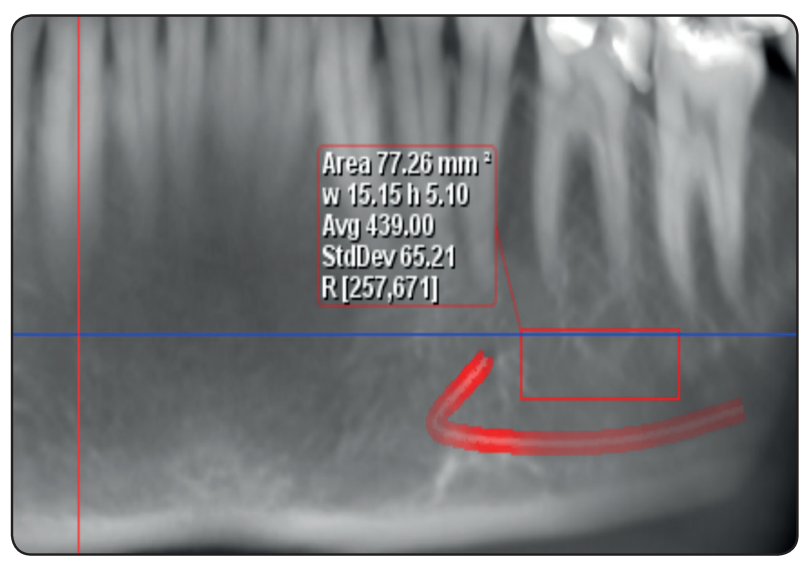

Fig. (2): measuring the relative bone density value in a rectangle below the molar area and above the inferior mandibular canal with dimension $0.5 \times 1.5 \mathrm{~cm}$ 
TABLE (1) Comparison between Angles in the Three study Group

\begin{tabular}{|c|c|c|c|c|}
\hline & Group & Mean & SD & F (p) \\
\hline \multirow{4}{*}{ Angle } & I ( $\left.\mathrm{N}_{1}=24\right)$ & 126.2708 & 2.25995 & \multicolumn{1}{|c|}{} \\
\cline { 2 - 4 } & II $\left(\mathrm{N}_{2}=24\right)$ & 130.6875 & 6.73029 & $\begin{array}{c}29.862 \\
(\mathrm{p}<0.001)^{*}\end{array}$ \\
\cline { 2 - 4 } & III $\left(\mathrm{N}_{3}=24\right)$ & 120.2583 & 3.95836 & \\
\hline
\end{tabular}

$F:$ for ANOVA test $\quad$ *: significant at $p<0.05$

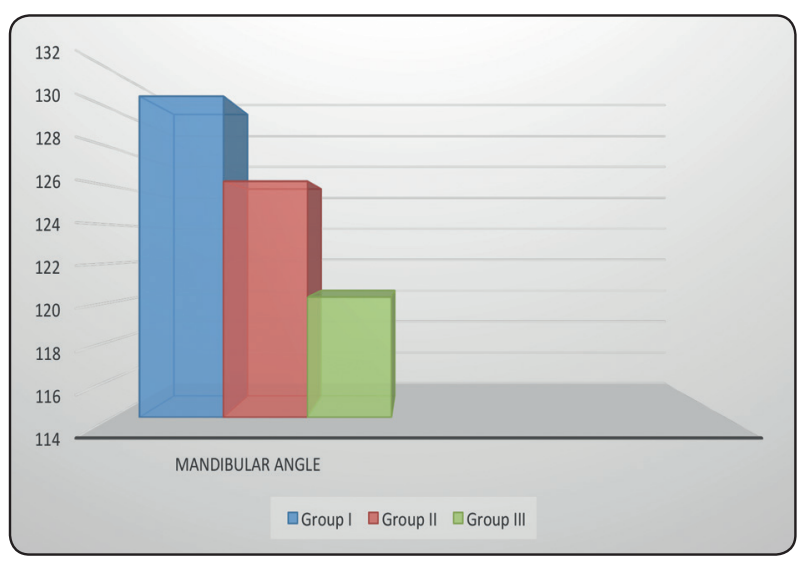

Chart 1: summary of the measured means of the angles in the 3 groups

TABLE (2) Post Hoc Comparison between the Angles of the Three study groups

\begin{tabular}{|c|c|c|}
\hline & II & III \\
\hline I & P $<0.001^{*}$ & $0.005^{*}$ \\
\hline II & & $\mathrm{P}<0.001^{*}$ \\
\hline
\end{tabular}

*: significant at $p<0.05$

Regarding the measured density in the 3 groups the ANOVA test showed a significant difference between the 3 groups. As shown in table 3 The highest density was measured in group A the normal group, while the least was measured in group $\mathrm{C}$ (RA more than 10 years). As shown in chart 2. Further analysis between each group and the second showed a significant difference between each group as shown in table 4.
TABLE (3) Comparison between Density in the Three study Group

\begin{tabular}{|c|c|c|c|c|}
\hline & Group & Mean & SD & $\mathrm{F}(\mathrm{p})$ \\
\hline \multirow{3}{*}{ Density } & $\mathrm{I}\left(\mathrm{N}_{1}=24\right)$ & 558.6667 & 109.83809 & \multirow{3}{*}{$\begin{array}{c}24.801 \\
(p<0.001)^{*}\end{array}$} \\
\hline & II $\left(\mathrm{N}_{2}=24\right)$ & 478.2042 & 126.76037 & \\
\hline & III $\left(\mathrm{N}_{3}=24\right)$ & 355.4583 & 47.63811 & \\
\hline
\end{tabular}

$F:$ for ANOVA test $\quad *$ : significant at $p<0.05$

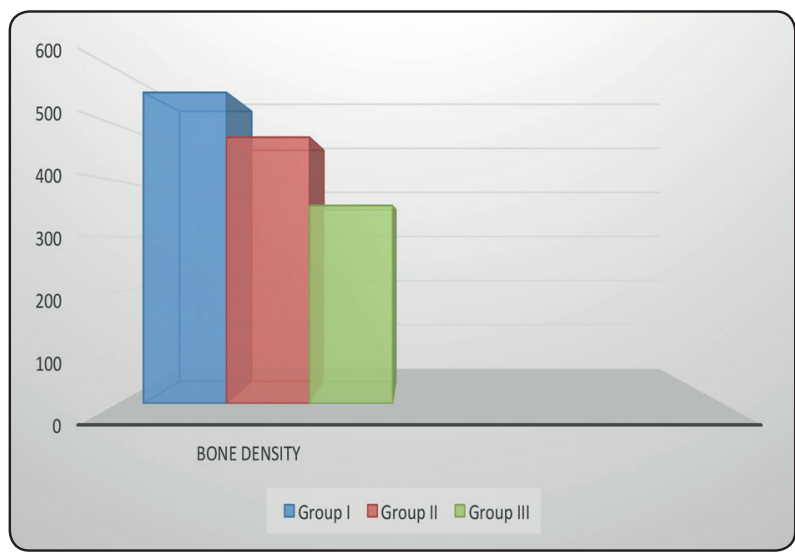

Chart (2) summary of the measured density in the 3 groups

Table 4: Post Hoc Comparison between the Density of the Three study groups

\begin{tabular}{|c|c|c|}
\hline & II & III \\
\hline I & $0.020^{*}$ & $\mathrm{P}<0.001 *$ \\
\hline II & & $\mathrm{P}<0.001 *$ \\
\hline
\end{tabular}

Turkey HSD post Hoc test $\quad$ *: significant at $p<0.05$

\section{DISCUSSION}

The typical radiographic findings for the RA patients regarding the $\mathrm{TMJ}$ are joint-space narrowing and condylar erosion, flattening, and sclerosis. ${ }^{12}$ All these findings result in a malocclusion (skeletal Class-II) combined with anterior open-bite. ${ }^{4}$ This skeletal malocclusion results in change in the mandibular angles, which was chosen in this study 
to measure the effect of the duration of the RA on the TMJ

The results of the current study showed that there is a high statistically significant correlation $(\mathrm{p}<0.05)$ between the RA duration and the mandibular angle which marginally decreases as the disease duration increase in spite of the patient is under treatment. (chart 1). These results confirm that there is change in the TMJ as decreasing the mandibular angle convert the case more toward the skeletal class II.

Many previous studies, proved the TMJ involvement in patients with RA. It has been reported to be between $2-98 \% .{ }^{13}$ Also the severity of damage in the TMJ seems to be directly proportion with the severity of RA as well as the level of RF (rheumatoid factor), ESR (erythrocyte sedimentation rate) and CRP (C-reactive protein), all these factors increase with the duration of the RA..$^{14,15}$

Our results were in accordance with the study of Y.C. Lin et al $2007^{15}$, who stated that $29.6 \%$ of RA patients showed TMJ symptoms within the first year from the onset of the generalized disease. However, $51.8 \%$ of these patients showed TMJ symptoms more after the first year from the onset of RA, with up to $22.2 \%$ of cases showing their symptoms after 5 years or more.

The current study also demonstrated a decrease in the bone density with the duration of the RA. These results were in agreement with findings of several previous publications that assessed bone loss in RA. ${ }^{16,17,18}$ Our findings support the results of some previous studies and add to the literature by extending on the positive relationship between disease duration and the bone density.

In a study on postmenopausal RA disability and cumulative dose of glucocorticosteroids were considered as the key determinants of bone loss. ${ }^{19}$ This study, however, was limited for other associated factors of osteoporosis except disease duration.

The current study agrees with a study stated that decrease in the density of the bone in the hand, evaluated by DXA, during early stage of RA with an average disease duration of $1 / 2$ year duration..$^{20}$ The decrease of bone density in the hand was also evaluated using digital $\mathrm{x}$-ray, after a year in RA patients with a disease duration 0-4 years was an independent predictor of TMJ damage on the basis at 5 and 10 years. ${ }^{21}$

Hoff et al. 2007 reported that the bone density of the hand did not change for 2 years in RA patients with a disease duration of 9 year; furthermore, the change in bone density of the hand was $-0.96 \%$ with a disease duration of less than three years and $0.24 \%$ with a disease duration more than three years..$^{22}$ The different in results may be due to different site and the effects of common mechanical factors can be considered.

\section{CONCLUSION}

There is a high correlation between the duration of the RA and the bone density and also an effect on the TMJ which affects the mandibular angle and converts the patient occlusion into skeletal class II despite receiving a treatment.

\section{LIMITATION:}

The limitation in this study that it is only a radiographic evaluation, we need further studies contain the clinical sign and symptoms as well as laboratory investigation to correlate them all together.

\section{REFERENCES:}

1. Takaaki Ueno, Toshimasa Kagawa, Miwa Kanou, Nobuhisa Ishida, Takashi Fujii, Joji Fukunaga, Nobuyoshi Mizukawa, Toshio Sugahara. Pathology of the temporomandibular joint of patients with rheumatoid arthritis - case reports of secondary amyloidosis and macrophage populations. Journal of Cranio-Maxillofacial Surgery (2003) 31, 252-256

2. Momoko Yokokoji, Takehiro Fujimoto, Morimichi Ohya, Minoru Ueda. Dental Implants for an Elderly Patient with Rheumatoid Arthritis taking Long-term Steroids. Asian J Oral Maxillofac Surg. 2009;21:123-126. 
3. Helenius LM, Hallikainen D, Helenius I, Meurman JH, $\mathrm{K} €$ on€onen $\mathrm{M}$, Leirisalo-Repo $\mathrm{M}$, et al. Clinical and radiographic findings of the temporomandibular joint in patients with various rheumatic diseases. A case-control study. Oral Surg Oral Med Oral Pathol Oral Radiol Endod 2005;99:455-63.

4. Smiler DG. Evaluation and treatment planning. J Calif Dent Assoc. 1987;15:35-41

5. Pers JO, Saraux A, Pierre R, Youinou P. Anti-TNF-alpha immunotherapy is associated with increased gingival inflammation without clinical attachment loss in subjects with rheumatoid arthritis. Journal of Periodontology 2008;79(9):1645-51

6. Ouédraogo D-D, et al. Periodontal disease in patients with rheumatoid arthritis in Sub-Saharan Africa: A case-control study. Joint Bone Spine (2016)

7. Yavuzyılmaz E, Yamalık N, C, algu“ ner M, Ersoy F, Baykara M,Yeniay I, et al. Clinical and immunological characteristics of patients with rheumatoid arthritis and periodontal disease. Journal of Nihon University School of Dentistry 1992;34(2):89-95.

8. Mercado F, Marshall RI, Klestov AC, Bartold PM. Is there a relationship between rheumatoid arthritis and periodontal disease? Journal of Clinical Periodontology 2000;27(4):267-72.

9. Mercado FB, Marshall RI, Klestov AC, Bartold PM. Relationship between rheumatoid arthritis and periodontitis. Journal of Periodontology 2001;72(6):779-87.

10. Yavuzyılmaz E, Yamalık N, C, algu“ ner M, Ersoy F, Baykara M, Yeniay I. Clinical and immunological characteristics of patients with rheumatoid arthritis and periodontal disease. The Journal of Nihon University School of Dentistry 1992;34(2):89-95.

11. Pınar Gumu s, Eralp Buduneli, Bas,ak Biyıkog lu, Kenan Aksu, Fulden Sarac, Nurcan Buduneli, David F. Lappin. Gingival crevicular fluid and serum levels of APRIL, BAFF and TNF-alpha in rheumatoid arthritis and osteoporosis patients with periodontal disease. archives of oralbiology 58 (2013) 1302-1308.)

12. Ramos-Remus C, Major P, Gomez-Vargas A, Petrikowski G, Hernandez-Chavez A, Gonzalez-Marin E, et al. Temporomandibular joint osseous morphology in a consecu- tive sample of ankylosing spondylitis patients. Ann Rheum Dis 1997;56:103-7

13. Ko“no“nen M, Wenneberg B, Kallenberg A. Craniomandibular disorders in rheumatoid arthritis, psoriatic arthritis, and ankylosing spondylitis. A clinical study. Acta Odontol Scand 1992; 50:281-7.

14. Liu HT, Chiu FY, Chen CM, Chen TH. The combination of systemic antibiotics and antibiotics impregnated cement in primary total knee arthroplasty in patients of rheumatoid arthritis - evaluation of 60 knees. J Chin Med Assoc 2003;66:533-6

15. Yi-Chun Lin, Ming-Lun Hsu, Jih-Sheng Yang, Toong-Hua Liang, Sun-Long Chou, Hsiao-Yi Lin. Temporomandibular Joint Disorders in Patients with Rheumatoid Arthritis. J Chin Med Assoc 2007;70(12):527-534.

16. Gu“ ler-Yu“ ksel M, Bijsterbosch J, Goekoop-Ruiterman YP. Changes in bone mineral density in patients with recent onset, active rheumatoid arthritis. Ann Rheum Dis. 2009 Mar;68:297e299.

17. Cairns AP, McVeigh JG. A systematic review of the effects of dynamic exercise in rheumatoid arthritis. Rheumatol Int 2009;30:147e158.

18. Behzad Heidari, Alireza Firouzjahi, Maryam Haj Mirghssemi, Parham Heidari, Niloofar Hakimi, Karim Hajian-Tilaki. Relationship between bone mineral density and duration of rheumatoid arthritis. Iindian journal of rheumatology 10 ( 2015 ) 10-15

19. Hall GM, Spector TD, Griffin AJ, Jwad AS, Hall ML, Dole DV. The effect of rheumatoid arthritis and steroid therapy on bone density in postmenopsusal women. Aryhritis Rheum36:1510;1993 .e1516.

20. Bejarano V, Hensor E, Green M, et al. Relationship between early bone mineral density changes and long-term function and radiographic progression in rheumatoid arthritis. Arthritis Care Res (Hoboken). 2012;64:66-70.

21. Hoff M, Haugeberg $\mathrm{G}$, Odegård $\mathrm{S}$, et al. Cortical hand bone loss after 1 year in early rheumatoid arthritis predicts radiographic hand joint damage at 5-year and 10-year follow-up. Ann Rheum Dis. 2009;68:324-329.

22. Hoff M, Haugeberg G, Kvien TK. Hand bone loss as an outcome measure in established rheumatoid arthritis: 2-year observational study comparing cortical and total bone loss. Arthritis Res Ther. 2007;9:R81. 